\title{
DESAFIOS E ESTRATÉGIAS DA AGRICULTURA FAMILIAR NOS ASSENTAMENTOS RURAIS NA FRONTEIRA AGRÍCOLA
}

\section{CHALLENGES AND STRATEGIES OF FAMILY FARMING IN ASSENTAMENTOS RURAIS ON THE AGRICULTURAL FRONTIER}

\author{
Taiana Ciscotto Martins Lourenço \\ Universidade Federal do Rio de Janeiro, Núcleo de Estudos Geoambientais, Rio de Janeiro, RJ, Brasil \\ taiana.ciscotto@gmail.com
}

\begin{abstract}
Resumo
O presente artigo tem como objetivo analisar as repercussões territoriais do avanço da fronteira agrícola sobre os assentamentos rurais do Xingu-Araguaia (Mato Grosso) e sobre a agricultura familiar. Para tanto, enfatiza-se o município de Querência por ser nele onde a cadeia produtiva de grãos encontra-se mais consolidada nessa região. Além disto, neste município existem cinco assentamentos com aproximadamente 1219 famílias onde têm se constatado nos últimos anos uma rápida conversão de pastagens pelo cultivo de grãos, sobretudo a soja. A metodologia do artigo é composta por revisão bibliográfica, levantamento de dados secundários e realização de pesquisa empírica para obtenção de dados primários. $\mathrm{O}$ trabalho permitiu constatar que ao contrário do que ocorre entre os assentados que optam pela produção de commodities, os assentados que se mantêm vinculados à prática da agricultura familiar buscam parcerias locais visando a troca de saberes, fortalecendo a coesão territorial entre essas famílias e marcando a conturbada coexistência de distintos interesses e atores na fronteira agrícola.
\end{abstract}

Palavras-chave: Assentamentos rurais. Fronteira agrícola. Agricultura familiar. XinguAraguaia.

\begin{abstract}
This article aims to analyze the territorial repercussions of the advance of the agricultural frontier on the assentamentos rurais of Xingu-Araguaia (Mato Grosso) and family farming. To this end, the municipality of Querência is emphasized as it is where the grain production chain is most organized and consolidated in this region. Besides, in this municipality, there are five assentamentos with approximately 1219 families. In the last few years, there has been a rapid conversion of pastures by the cultivation of grains, especially soybeans. The methodology of the article is composed of bibliographic review, collection of secondary data and conducting empirical research to obtain primary data. The work show that, contrary to what happens among settlers who choose to produce commodities, settlers who remain linked to the practice of family farming seek local partnerships in search of knowledge exchange, strengthening territorial cohesion between these families and marking the troubled coexistence of different interests and actors on the agricultural frontier.
\end{abstract}


Keywords: Assentamentos rurais. Agricultural frontier. Family farming. XinguAraguaia.

\section{Introdução}

Ainda que o termo agricultura familiar já estivesse nas pautas e propostas governamentais desde os anos 1990 (FERNANDES, 2014), foi apenas no ano de 2006 que esta categoria tornou-se legitimamente reconhecida através da Lei 11.326, que estabeleceu as diretrizes para formulação da Política Nacional da Agricultura Familiar e os critérios para identificação desse público. Muitos avanços foram conquistados por esses atores, sendo o Programa Nacional da Agricultura Familiar (PRONAF) o mais reconhecido deles e cuja importância extrapola os aspectos produtivos ao considerar a importância social desses atores e ao valorizar o meio rural enquanto um lugar de vida e de trabalho. Embora tenha sido oficialmente criado no governo de Fernando Henrique Cardoso, foi durante o primeiro mandato do ex-presidente Luís Inácio Lula da Silva que o programa foi fortalecido, diversificado e ampliado para todo o território nacional, destinando, em 2010, um montante de aproximadamente 12 trilhões de reais para esse público, segundo o Banco Central.

Outra importante política para essa categoria são os projetos de assentamentos rurais (PA's), entendidos como uma conquista política da classe trabalhadora expropriada que, através das ocupações de terra, logrou êxito no reconhecimento, por parte do Estado, desses territórios enquanto espaços dedicados à prática da agricultura familiar. Essa política é de natureza redistributiva, polarizada e formada por conflitos e consensos entre diversos atores sociais (Estado, trabalhadores rurais, movimentos sociais, proprietários de terra e etc.) (MONTE, 2013) e reflete a força e a organização dessa classe na reivindicação pelo cumprimento da função social da terra.

O contexto em que as diversas políticas públicas são elaboradas e executadas relaciona-se ao ambiente institucional vigente, o que implica necessariamente em uma intencionalidade e escolha dos que detêm o poder num determinado período. Isso é relevante para entender a atual situação da agricultura familiar e das políticas para esse público, que têm sofrido impactantes reveses principalmente a partir de 2016, com a instabilidade política que culminou no impeachment da ex-presidente Dilma Rousseff. Importantes ações para esta categoria têm sofrido cortes orçamentários significativos, 
prejudicando o andamento das atividades e projetos para esses atores ${ }^{1}$ que ameaçam sua autonomia e reprodução social.

Ao lado desses cortes orçamentários, verifica-se um aumento de $54 \%$ dos conflitos no campo entre 2010 e 2019 e, somente neste último ano, foram registradas 1206 ocorrências de conflitos por terra, 32 assassinatos e 30 tentativas de assassinatos no campo brasileiro (CPT, 2020). Em contrapartida, a fronteira agrícola permanece em progressiva expansão, convertendo áreas consideradas subutilizadas para a produção de commodities, reforçando o papel do Brasil na divisão internacional do trabalho enquanto fornecedor de matérias-primas com baixo valor agregado.

Diante desse contexto, o presente artigo traz alguns resultados da tese de doutorado da autora ${ }^{2}$ e tem como objetivo discutir alguns desdobramentos do avanço da fronteira agrícola na região Xingu-Araguaia, especificamente sobre a agricultura familiar praticada nos assentamentos do município de Querência, em Mato Grosso. Como será discutido adiante, a escolha por este município não foi aleatória, visto que é nele onde a cadeia produtiva de grãos encontra-se mais consolidada e organizada em aspectos técnicos e produtivos dentro deste recorte. A principal hipótese levantada é que a fronteira agrícola provoca uma desarticulação das cadeias produtivas típicas da agricultura familiar, enfraquecendo os elos que os articulam e fragilizando o assentamento enquanto território da agricultura familiar.

A metodologia deste trabalho é composta por técnicas de pesquisa qualitativa, a partir da observação das dinâmicas, participação, descrição e análise. Para tanto, foram realizados quatro trabalhos de campo entre 2016 e 2019 para a obtenção dos dados primários, alcançados a partir de entrevistas livres e semiestruturadas e da participação em eventos locais que reuniram assentados. Aos dados primários soma-se o levantamento de dados secundários em diversas fontes pertinentes ao trabalho, como indicadores da produção de commodities (área plantada e quantidade produzida), conflitos por terra, características dos assentamentos, mudanças do uso e cobertura do solo, dentre outros. Tais dados foram dispostos ao longo do trabalho na forma de tabelas, gráficos e mapas

\footnotetext{
${ }^{1}$ Alguns dos principais cortes (no período entre 2015 e 2018) que atingem diretamente o público da agricultura familiar são nas ações de: obtenção de terras para a reforma agrária e assistência técnica e extensão rural (ambas com redução de $96 \%$ ), promoção e fortalecimento da agricultura familiar (redução de 88\%) e desenvolvimento dos assentamentos (redução de 71\%) (TEIXEIRA e INTINI, 2017).

2 Tese defendida em fevereiro de 2020 no Programa de Pós-Graduação em Geografia da Universidade Federal do Rio de Janeiro, intitulada: "De desterritorializados sem terra a desterritorializados com terra: uma análise dos assentamentos rurais do nordeste mato-grossense".
} 
conforme melhor conveniência. A análise dos dados primários e secundários foi amparada por uma revisão bibliográfica e conceitual que buscou cercar as principais noções, categorias e conceitos discutidos ao longo do trabalho, privilegiando uma abordagem interdisciplinar da temática.

Vale ressaltar que a dificuldade logística foi a principal barreira para a visita dos assentamentos dessa região, pois, em geral, os PA's são distantes mais de $100 \mathrm{~km}$ dos núcleos urbanos dos municípios e, em sua maioria, são integralmente percorridos em estradas sem pavimentação. Neste sentido, encontrar outras estratégias foi fundamental para o êxito dos trabalhos de campo, e a principal delas foi buscar parceiros nos movimentos sociais, como a Comissão Pastoral da Terra (CPT) em Porto Alegre do Norte e organizações não-governamentais locais, como a Associação Nossa Senhora de Assunção (Ansa) e a Articulação Xingu-Araguaia (AXA).

Dito isto, o presente trabalho está dividido em três seções, além desta introdução e das considerações finais. A primeira apresenta alguns dos principais processos e atores responsáveis pelo histórico da formação territorial do Xingu-Araguaia, entendendo que tais processos estavam intimamente relacionados a uma estratégia geopolítica de ocupação dos "vazios demográficos" com forte apoio de grandes empresários e proprietários de terra, o que desencadeou intensos conflitos agrários a partir da instalação dos projetos agropecuários. Num segundo momento, direciona-se a análise para o período contemporâneo de avanço da fronteira agrícola evidenciando por meio de dados primários e secundários que a conversão de pastagens pelo cultivo de grãos vem sendo realizada nos últimos dez anos dentro dos assentamentos no município de Querência, haja vista o esgotamento de áreas fora desses projetos. Por fim, na terceira seção, discute-se alguns dos principais desdobramentos do avanço do agronegócio sobre a agricultura familiar praticada dentro dos assentamentos naquele município.

\section{Aspectos históricos e socioterritoriais formadores do Xingu-Araguaia}

A região do Xingu-Araguaia localiza-se no nordeste mato-grossense e possui mais de 120 mil habitantes distribuídos por quinze municípios e tem a BR-158 como principal eixo logístico rodoviário (Mapa 1). É nesta região onde também se concentra aproximadamente $25 \%$ dos projetos de assentamentos rurais de todo o estado de Mato Grosso e os aspectos históricos constituidores dessa área são fundamentais para explicar essa concentração. 
Mapa 1 - Localização e municípios da região Xingu-Araguaia (MT)

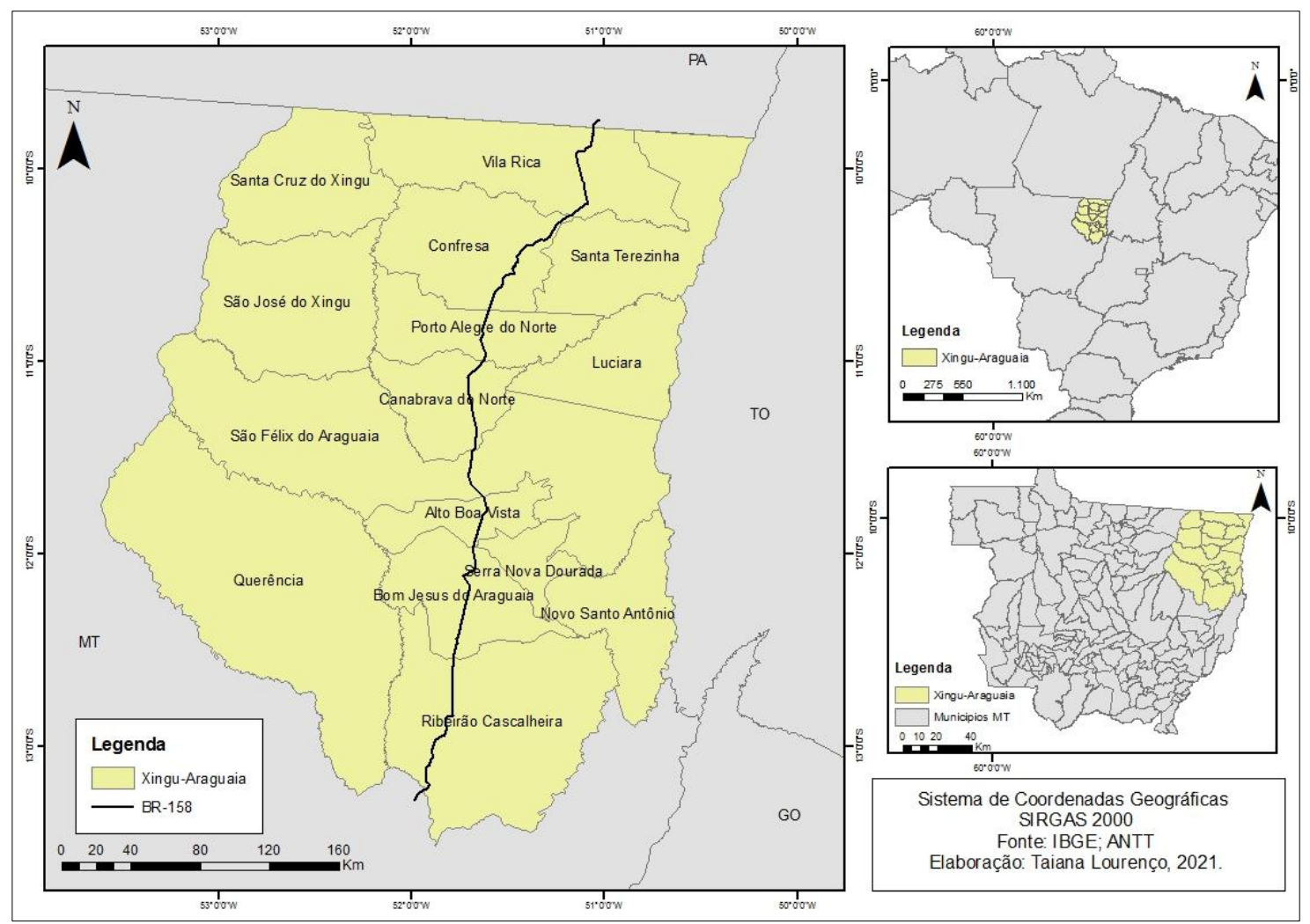

Fonte: IBGE; ANTT.

Org.: Taiana Lourenço, 2019.

Esta região vivenciou um movimento de ocupação (no que se refere à ocupação por atividades capitalistas) mais tardio quando comparado a outras regiões do estado. Foi na década de 1940 com a Marcha para o Oeste que teve início a atuação militar nesta região, a partir da criação da Expedição Roncador-Xingu (ERX) que dotou aquele espaço de vias de comunicação, explorou suas riquezas minerais e desconsiderou a existência de mais de dezesseis povos indígenas (OLIVEIRA, 2016), alterando irreversivelmente a dinâmica territorial ali estabelecida. Além disso, neste mesmo período, diversos grupos de posseiros vindos de Goiás, Minas Gerais e de estados nordestinos chegaram à região em busca de terras onde pudessem conquistar melhorias nas condições de suas vidas.

Algumas décadas mais tarde, a região também foi marcada pela implementação de projetos de colonização através de contratos de concessão de terras públicas e devolutas para empresas particulares. Esses projetos, segundo Oliveira (2016, p.157), foram a "alternativa escolhida pelas classes dominantes para evitar simultaneamente a necessária reforma estrutural do campo e ao mesmo tempo suprir-se de força de trabalho para seus projetos de fronteira”. Ao todo, 33 empresas privadas foram registradas junto 
ao Instituto Nacional de Colonização e Reforma Agrária (Incra) de Mato Grosso nas décadas de 1970 e 1980, sendo responsáveis pela implementação de 88 projetos de colonização no estado que abrangeram 3,25 milhões de hectares e receberam aproximadamente 20 mil famílias de colonos, a grande maioria proveniente da região Sul do país (MORENO, 2007).

Agrupados em agrovilas que ajudaram a organizar a produção e a reprodução do espaço urbano e rural, os migrantes sulistas utilizaram máquinas no plantio e colheita de arroz e tal produção se tornou estratégica, tanto do ponto de vista ecológico quanto econômico, porque ajudaria na transição do solo para receber pastagens para a pecuária e outras produções, como soja e milho (JEPSON, 2006). Ao retratar essa migração, Martins (2012, p.111) afirma que a incorporação dessas técnicas pelos migrantes era o meio de "conciliar a relação entre a terra e o trabalho, de maneira equilibrada", uma vez que a migração era justificada como uma possibilidade de melhoria das condições de vida tendo dois elementos centrais para o alcance desse objetivo: família e trabalho.

No entanto, foi a partir da década de 1970 que a região se transformou mais rapidamente devido a um conjunto de medidas e programas federais que incidiram diretamente sobre a questão fundiária e produtiva regional. Uma dessas medidas foi a federalização de 60\% das terras de Mato Grosso através do Decreto-Lei n¹164/71, que previa que terras situadas às margens das rodovias federais, na Amazônia Legal, numa extensão de $100 \mathrm{~km}$ de cada lado do seu eixo, bem como nas áreas situadas ao longo das fronteiras internacionais passariam à jurisdição do Incra. Outra medida foi a criação de diversos programas de desenvolvimento dirigidos na esteira do processo de modernização da agricultura em curso desde a década de 1960, como o Programa de Integração Nacional (PIN), o Programa de Pólos Agropecuários e Agrominerais da Amazônia (Poloamazônia) e o Programa de Desenvolvimento dos Cerrados (Polocentro) que foram importantes para o financiamento de estratégias que consolidaram a construção da BR-158.

Esses programas marcaram o momento em que o capital multinacional começou a se interessar pela terra como alternativa de investimento (BECKER, 2015), tendo início a territorialização de grandes monopólios na Amazônia e no Centro-Oeste via subsídios da Superintendência do Desenvolvimento da Amazônia (Sudam) e Superintendência do Desenvolvimento do Centro-Oeste (Sudeco), que incentivaram a apropriação e concentração de terra e capital nas mãos de firmas sediadas no Centro-Sul do país. Segundo Moreno (2007), somente para Mato Grosso foram destinados 23,06\% de todos 
os incentivos fiscais comprometidos pela Sudam, sendo o segundo estado que mais recebeu tais recursos.

No Xingu-Araguaia, esses empreendimentos utilizaram o desmatamento, a pecuária extensiva e a peonagem como as principais estratégias territoriais para o efetivo controle e domínio das terras. Segundo Oliveira (2016), foi através da "pata do boi” que essas terras foram apropriadas pelos projetos agropecuários, cujo interesse se dava mais pelos incentivos fiscais do que pela própria atividade econômica. Foi, no entanto, através da figura do peão, que as terras foram amansadas, ou seja, desmatadas. Esse trabalhador, frequentemente migrante, era despossuído de documentos e de contrato de trabalho e, muitas vezes, era elevado à condição de jagunço, o que de certa forma, representava uma elevação em seu status social. Tal condição também foi evidenciada por Martins (2012, p.85) que, em sua análise sobre a expansão da fronteira, afirmou que o "objetivo da expansão territorial não era a produção pecuária, mas a produção de fazendas" pela possibilidade de extrair a renda da terra através de mecanismos e processos de acumulação primitiva, como o trabalho escravo utilizado, sobretudo, para o desmatamento e formação de pastagens para o gado³.

Somente nos municípios de Barra do Garças, São Félix do Araguaia e Luciara foram aprovados pela Sudam 96 projetos agropecuários de 1966 a 1978, sendo que alguns destes projetos se tornaram mundialmente conhecidos pela extensão territorial que controlavam e pelas práticas presentes nas relações de trabalho. É o caso da Agropecuária Suiá-Missu (500 mil ha), da Cia de Desenvolvimento do Araguaia, a Codeara (150 mil ha), e a Agropecuária Nova Amazônia, a Frenova (68 mil ha).

Ao fixar as cercas, um dos principais símbolos territoriais do latifúndio, os projetos agropecuários definiam, ao mesmo tempo, um ritmo na sua territorialização e um controle sobre um espaço que antes era o espaço de vida e de produção, ou seja, o território de posseiros e indígenas, obrigando-os a agir reativamente. As práticas das agropecuárias para promover a expulsão dos posseiros das terras eram diversificadas: destruição de cercas colocadas pelos posseiros para a proteção do roçado, queima de casas e de roças, controle do acesso às roças, ameaças e intimidação feitas por jagunços, assassinatos, denúncias afirmando que os posseiros eram comunistas e subversivos e

\footnotetext{
${ }^{3}$ Dados de Martins (2012) indicam que até o ano de 1995, 72,7\% dos peões escravizados na Amazônia eram empregados nessas duas atividades. Segundo Rivière d'Arc e Apestéguy (1978) um peão era responsável por, em média, 600 cabeças de gado.
} 
pedidos de reintegração de posse como formas de afastar esses atores das leis vigentes (MARTINS, 1979). Do outro lado, havia a ação coletiva dos posseiros que se organizavam com a ajuda da Igreja católica, representada na região pela Prelazia de São Félix do Araguaia ${ }^{4}$ e seus missionários, criando um vínculo social fundamental para a resistência cotidiana. Nesse sentido, os conflitos que surgiam eram espontâneos e representavam uma resposta à falta de alternativas reais de manutenção do território (MARTINS, 1989).

Tais ações indicam a crescente abrangência da espacialização da luta pela terra que, segundo Fernandes (1998), é o resultado de um projeto de transformação para a conquista da condição de cidadãos. Em última instância, essa espacialização também se reafirma na contestação ao modelo político-econômico em vigência que expropriava (e continua expropriando) agricultores familiares e sem terra e que agrega setores da Igreja solidários a essa causa.

\section{O avanço da fronteira agrícola em Querência}

O histórico de ocupação do Xingu-Araguaia se pautou em um processo direcionado por grandes proprietários de terra, empresários e pelo Estado que desconsiderou a organização espacial pré-existente, construída por comunidades indígenas e de posseiros e suas famílias, forjando materialidades e relações sociais e de poder que funcionam como rugosidades, ou seja, heranças socioterritoriais que se constituem em "coordenadas que orientam novas ações" (SANTOS, 2014, p. 203).

Diversas mudanças na paisagem ocorreram durante esse processo e, nos anos 2000, elas foram intensificadas, sobretudo pelo aceleramento da substituição da cobertura vegetal nativa pelas pastagens e pelos cultivos agrícolas, como pode ser observado no mapa 2. De acordo o Mapbiomas, entre 1985 e 2017, na região do Xingu-Araguaia houve uma redução de $42 \%$ na área de florestas e um aumento de $63 \%$ na área destinada às pastagens. Já a área destinada à agricultura passou de pouco mais de 260 hectares em 1985 para mais de 800 mil em 2017. Essa nova configuração dos modos de uso do solo mantém relação com o histórico da região, aprofundando a ideia de uma "vocação" para

\footnotetext{
${ }^{4}$ Criada em 1970, a Prelazia de São Félix do Araguaia se pautou no modelo de igreja popular do movimento da Teologia da Libertação.
} 

assentamentos rurais na fronteira agrícola

atividades agropecuárias, muito presente nos discursos para legitimar a implementação dos projetos agropecuários.

Mapa 2 - Xingu-Araguaia: cobertura e uso da terra nos anos 2000 e 2016
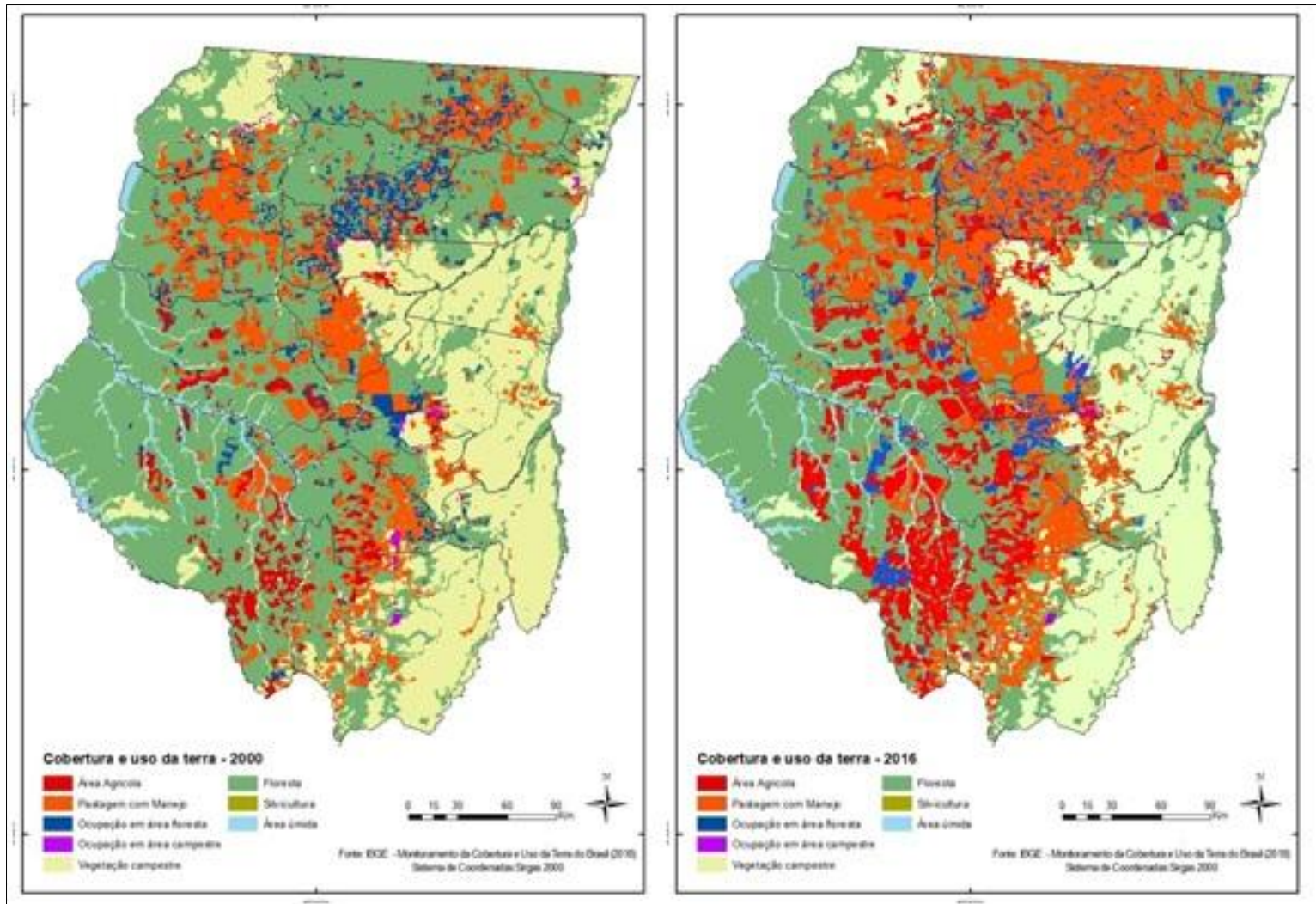

Fonte: IBGE;

Org.: Taiana Lourenço, 2019.

O contexto nacional e internacional dos anos 2000 foram decisivos para consolidar e acelerar as transformações territoriais do Xingu-Araguaia a partir do novo impulso que foi dado ao agronegócio via mecanismos estatais e privados, iniciando um período fortemente marcado pela financeirização da agricultura brasileira (DELGADO, 2012). Tal período também tem sido denominado por Svampa (2013) como "consenso das commodities" e o mapa anterior indica como ele modificou essa região, tornando plausível a afirmação de que existe uma continuidade no processo de avanço da fronteira agrícola e agropecuária sobre áreas de floresta.

Dentre os quinze municípios desse recorte, Querência é o mais relevante em termos de produção de commodities além de possuir uma peculiaridade: $40 \%$ da sua área é formada por terras indígenas, segundo a Plataforma da Agricultura Familiar de Mato Grosso (PEAF-/MT), sendo o município limítrofe ao Parque Indígena do Xingu. O 

assentamentos rurais na fronteira agrícola

gráfico a seguir revela a evolução da área ocupada por floresta, agricultura e pastagem entre os anos de 1985 e 2018 no município e indica que a preponderância das pastagens começa a se reduzir mais rapidamente conforme a área destinada aos cultivos agrícolas aumenta, o que ocorre mais fortemente a partir de 2003. Em sete anos, ou seja, em 2010, a curva ascendente da agricultura ultrapassa a de pastagens, já em redução desde 2004, indicando que há uma gradativa conversão das pastagens em lavouras de grãos.

Gráfico 1 - evolução da área (ha) de floresta, agricultura e pastagem em Querência de 1985-a 2018

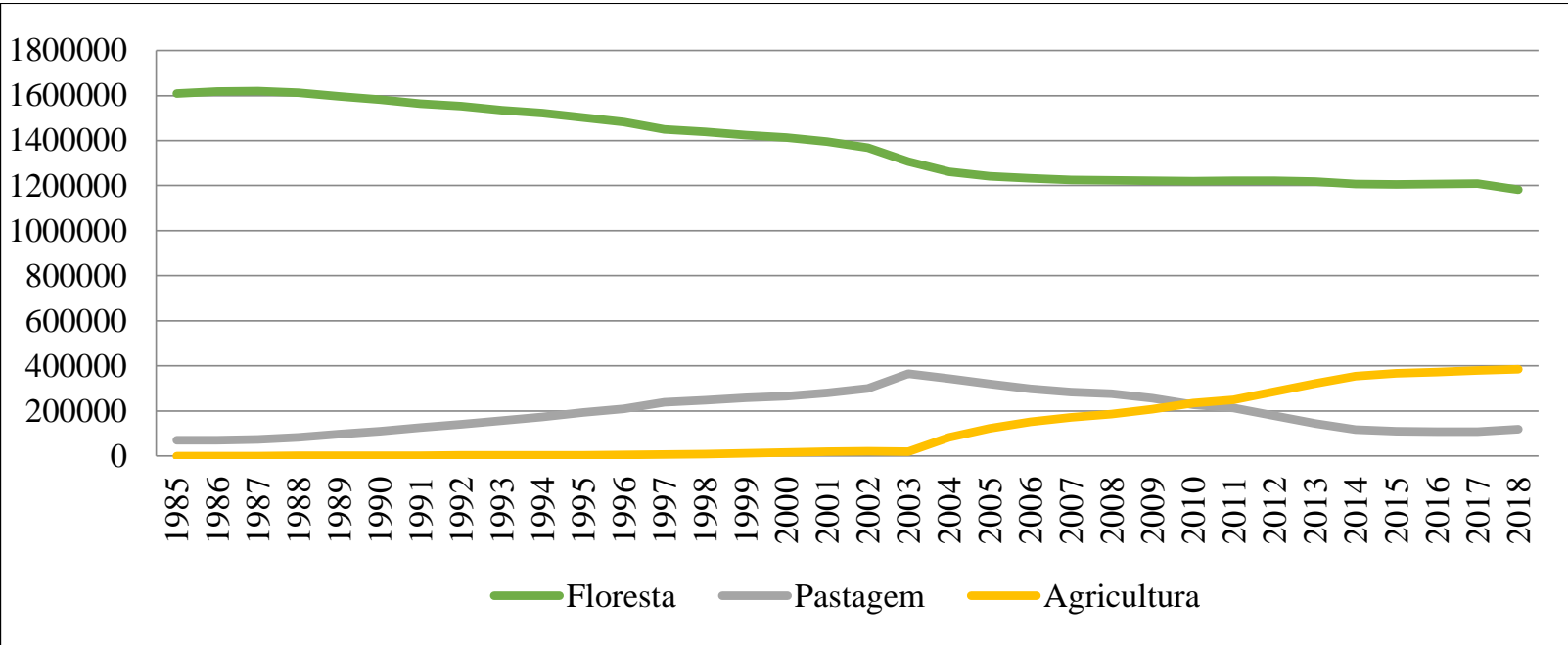

Fonte: Mapbiomas;

Org.: Taiana Lourenço, 2020.

Em relação à curva de florestas, observa-se que no período entre 1985 e 2004, ela caiu ininterruptamente ano a ano, passando de pouco mais de 16 milhões de hectares para aproximadamente 12 milhões de hectares em 2004, contabilizando uma queda de $22 \%$ na área de floresta do município. A partir de 2004, o ritmo dessa queda se desacelerou e essa área manteve-se praticamente estável, com 11 milhões de hectares em 2018. Todavia, observações realizadas durante os trabalhos de campo, confirmam que ainda existem áreas sendo abertas para a formação de pastagens e, sequencialmente, plantio de grãos (foto 1), inclusive dentro dos assentamentos.

Foto 1 - Lote recém-aberto dentro de área de assentamento em Querência 


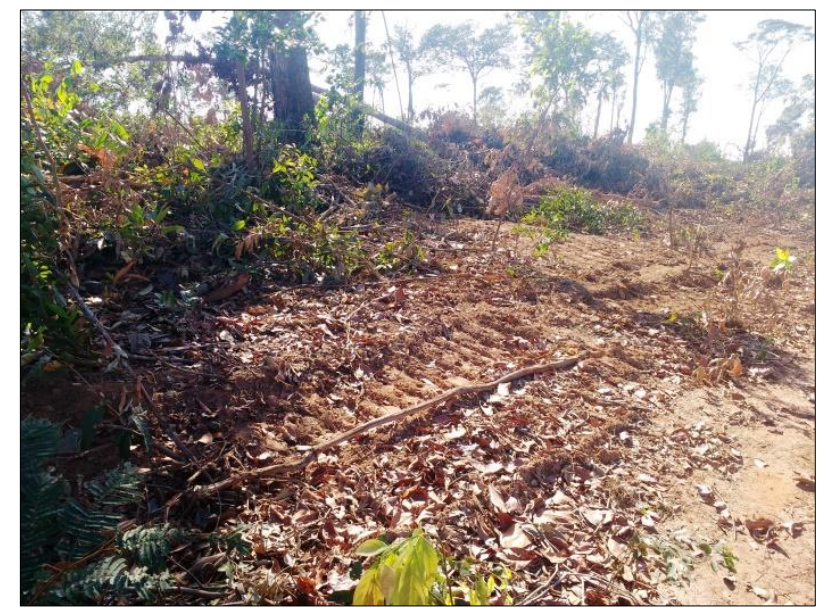

Fonte: Pesquisa de campo, 2019.

Autora: Taiana Lourenço.

Conforme Niederle e Wesz Jr (2018, p.142), o desmatamento de regiões da Amazônia Legal voltou a registrar aumentos após a aprovação do novo Código Florestal de 2012, o qual, "além de flexibilizar normas, anistiou infrações ambientais praticadas antes

$22 / 06 / 2008$, criando uma expectativa entre os desmatadores de que isto pode ocorrer novamente nos próximos anos". Tal expectativa está em vias de ser confirmada através da Medida Provisória $n^{\circ}$ 910/2019, que prevê a mudança do marco temporal para a regularização fundiária, que antes era referente ao ano de 2008 e, a partir dessa MP, passa a ser 05 de maio de 2014. Ademais, dados do Instituto Nacional de Pesquisas Espaciais (Inpe) indicam que entre 2017 e 2018, Querência apresentou o maior incremento de área desflorestada entre os municípios da região, com 70,6 km² desmatados.

Esses dados precisam ser lidos com base na conjuntura nacional de forte instabilidade política que indicam que a certeza de impunidade é um estímulo às práticas ambientais ilegais nessa região, conforme indica a fala de um entrevistado ${ }^{5}$ :

Aqui [em Querência] desde a época da eleição [de 2018], o desmatamento aumentou bastante dentro dos assentamentos. Bastante mesmo. Eu ando dentro dos assentamentos e vejo que desde então o pessoal tá abrindo área acreditando que no governo Bolsonaro isso não vai dar em nada, não vai ter multa (...) e isso aí é discurso dentro dos assentamentos, eu já ouvi já. Pessoal dentro do PA São Manoel comprou pacote, derrubou os quatro lotes. Foi derrubando tudo. (...) aí eu fui falar com os caras. E eles falaram que derrubaram mesmo pra colocar soja (...) (ENTREVISTADO 1, PESQUISA DE CAMPO, 2019).

\footnotetext{
${ }^{55}$ Entrevista obtida em maio de 2019 durante o $4^{\mathrm{o}}$ trabalho de campo realizado durante o doutorado. Por
} questões de segurança e privacidade, os nomes dos entrevistados citados neste artigo não serão revelados. 
A cadeia produtiva da soja é organizada e consolidada neste município e, embora a produção em si seja fundamental para a balança comercial do município, é o setor de serviços que corresponde a mais de $50 \%$ de sua receita anual, o que está intimamente relacionado às demandas dessa produção. Concentram-se, em Querência, escritórios das principais tradings (Grupo Amaggi, Louis Dreyfus Company, Bunge Alimentos S/A, Cargill Agrícola S/A e ADM do Brasil LTDA) e empresas do ramo de revendas de pacotes agrícolas (Agrológica, Agroamazônia, Lavoro Agrocomercial S.A, Sinagro, Rural Brasil S.A, Agroquima Produtos Agropecuários, Vale Produtos Agrícolas, Agrícola Alvorada LTDA, Pantanal Agrícola, etc..), além de 40 unidades armazenadoras de grãos cadastradas junto à Companhia Nacional de Abastecimento (Conab), o que retroalimenta a produção de commodities e, consequentemente, o avanço da fronteira agrícola neste município.

Entre 2000 e 2018, a produção de soja (toneladas) em Querência aumentou 2468\% e a área plantada (em hectares) cresceu 2331\% (PAM/IBGE) e boa parte dessa expansão da produção de grãos tem sido realizada dentro dos cinco assentamentos do município (tabela 1), visto o esgotamento de áreas passíveis de conversão fora dos projetos. A averiguação da veracidade desta informação aconteceu in loco em dois dos assentamentos do município e também pode ser corroborada a partir dos mapas a seguir.

Tabela 1 - Querência: principais características dos projetos de assentamentos

\begin{tabular}{cccc}
$\begin{array}{c}\text { Projeto de } \\
\text { Assentamento }\end{array}$ & $\begin{array}{c}\mathbf{N}^{\mathbf{o}} \text { de } \\
\text { famílias }\end{array}$ & $\begin{array}{c}\text { Área } \\
\text { (ha) }\end{array}$ & $\begin{array}{c}\text { Data de } \\
\text { criação }\end{array}$ \\
\hline PA Canaã I & 42 & 3769,14 & 2006 \\
PA São Manoel & 178 & 12756,1 & 1999 \\
PA Brasil Novo & 297 & 27905 & 1998 \\
PA Coutinho União & 171 & 15739,5 & 1995 \\
PA Pingos d'Água & 531 & 38409,5 & 1998 \\
\hline \multicolumn{5}{c}{ Fonte: Incra. }
\end{tabular}

Org.: Taiana Lourenço, 2020.

O mapa 3 refere-se ao PA Brasil Novo que é o assentamento mais distante do núcleo urbano do município, a aproximadamente $130 \mathrm{~km}$ de distância percorridos integralmente em via não pavimentada. Segundo o Ibama, este PA possuía, até 2019, 29 lotes embargados por infrações ambientais, a maioria delas referente ao desmatamento de 

assentamentos rurais na fronteira agrícola

áreas proibidas ${ }^{6}$. Observa-se que até 2008 , a pecuária era a atividade predominante no interior e adjacências do assentamento, o que vem se modificando progressivamente, fazendo com que, em 2018, as lavouras de soja já predominassem os limites e diversas áreas dentro do PA.

Mapa 3: evolução do uso e ocupação do solo no PA Brasil Novo (2008 e 2018).

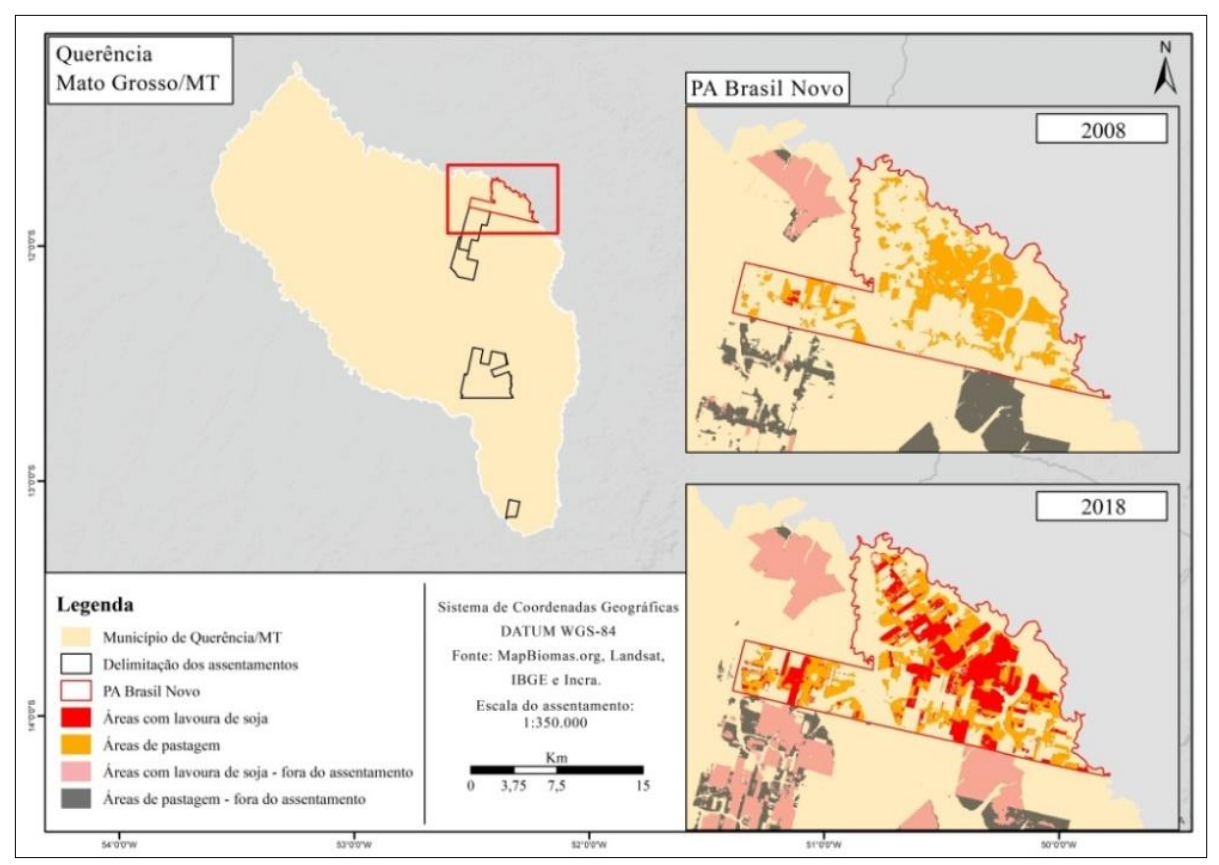

Fonte: Mapbiomas; Landsat; Incra; Ibge.

Org.: Karinna Paz; Taiana Lourenço (2019).

O mapa 4, por sua vez, indica a situação do PA Pingos d'Água, assentamento localizado a 20km do núcleo urbano de Querência e, embora a estrada não seja asfaltada, ela apresenta condições bem melhores do que a estrada que leva até o PA Brasil Novo, e isso se deve à necessidade de escoamento da produção de grãos do assentamento. A melhoria na qualidade da estrada foi garantida, segundo o entrevistado 1, devido à união dos produtores que possuem força política para garantir o atendimento de algumas das suas demandas junto ao poder público municipal.

Mapa 4: evolução do uso e ocupação do solo no PA Pingos d’Água (2008 e 2018).

\footnotetext{
${ }^{6}$ Infrações ambientais que constam no artigo 51 do Decreto $n^{\circ}$ 6.686, de 10 de dezembro de 2008: "destruir, desmatar, danificar florestas ou qualquer tipo de vegetação nativa ou de espécies nativas plantadas, objeto de especial preservação, em área de reserva legal ou servidão florestal, de domínio público ou privado não passíveis de autorização para exploração ou supressão ou sem autorização ou licença da autoridade ambiental competente ou em desacordo com a aprovação concedida, inclusive em planos de manejo florestal sustentável".
} 


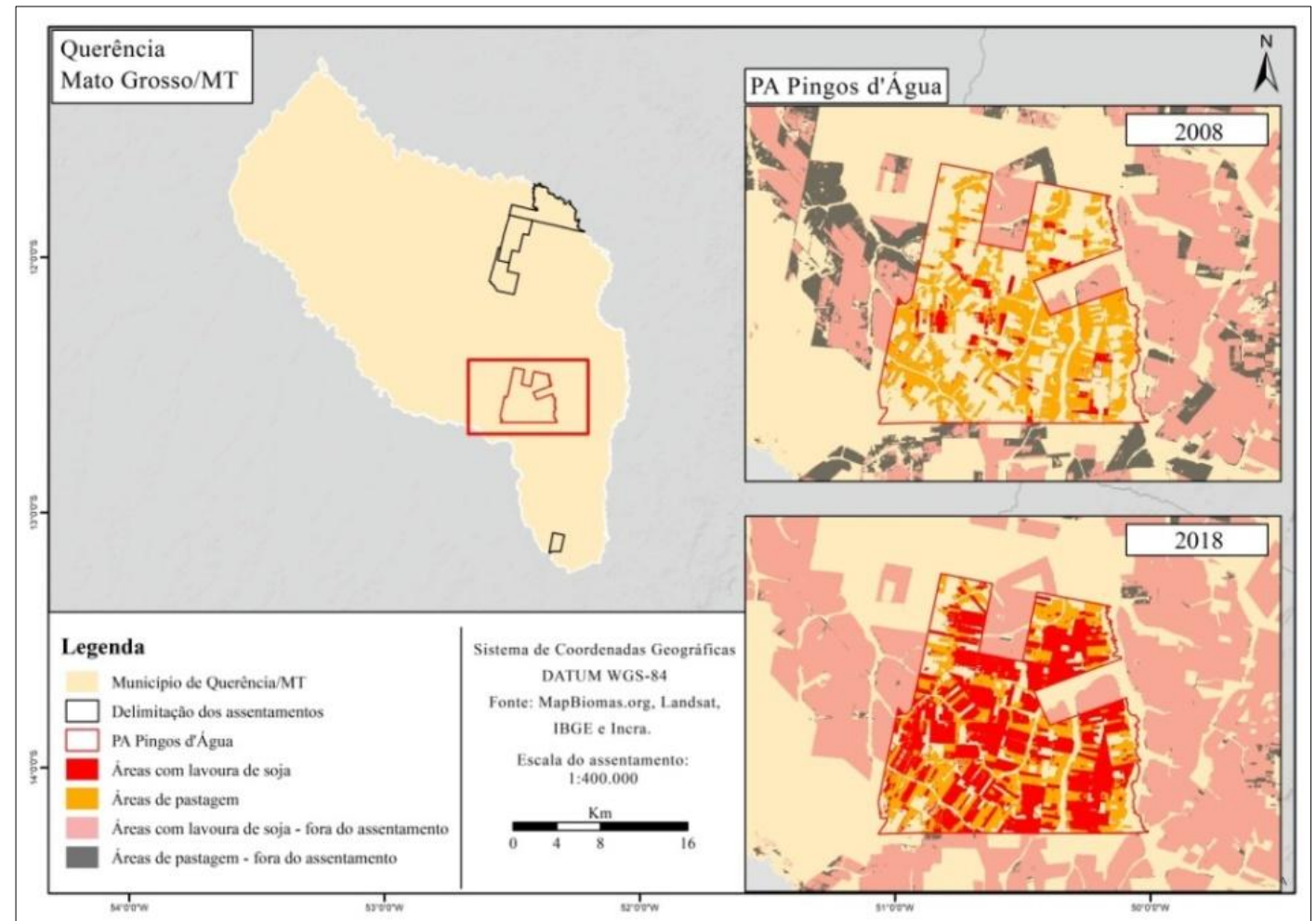

Fonte: Mapbiomas; Landsat; Incra; Ibge.

Org.: Karinna Paz; Taiana Lourenço (2019).

Neste PA, o índice de lotes embargados é elevado, chegando a mais de 1/5 do total de lotes. Isso significa que 116 unidades produtivas nesse assentamento estão nessa condição (Ibama, 2019), sendo que alguns casos já foram julgados, mas outros ainda aguardam o prosseguimento do processo. A área média dos lotes dos assentamentos nesse município é de 80 hectares e, salvo exceções, o perímetro embargado não corresponde à totalidade do lote.

Nota-se que em 2008, a pecuária era predominante dentro deste PA e ainda eram poucos os lotes voltados para a produção de soja, embora tal produção já fosse dominante nas adjacências do assentamento. Esse cenário, no entanto, é radicalmente modificado no intervalo entre 2008 e 2018, quando a produção de soja também passou a predominar dentro assentamento. Neste PA foi possível entrevistar um assentado gaúcho ${ }^{7}$ que possui 1500 hectares de lavoura de soja, praticada em sistema de parceria e arrendamento, o que até a promulgação da Medida Provisória nº759/2017 era considerado ilegal ${ }^{8}$. O perfil desse

\footnotetext{
${ }^{7}$ Os gaúchos se referem aos migrantes de qualquer estado do Sul do país que migraram para o Mato Grosso na década de 1980 e 1990 em busca de terras.

8 A medida provisória 759 foi convertida na lei 13.465 em 11 de julho de 2017 que, dentre outras atribuições, amplia as possibilidades de regularização fundiária em áreas urbanas e rurais e expande o Programa Terra Legal para todo o Brasil. Uma de suas medidas é abertura para a celebração de contratos
} 
assentado é encontrado por todo o assentamento: migrantes sulistas que chegaram à região na década de 1990 e a "desbravaram" e que atualmente são importantes atores locais que sustentam e defendem o agronegócio, nutrindo uma realidade de "pequeno fazendeiro" dentro do assentamento e que se contrapõe à figura do assentado praticante da agricultura familiar.

Ambos os mapas demonstram espacialmente as informações do gráfico 1, revelando que há uma gradativa conversão das pastagens desse município em lavouras de soja, o que, em última instância indica o comportamento do avanço da fronteira agrícola nessa região.

Sabe-se que a pecuária, sobretudo a leiteira, é um importante fator gerador de renda para os agricultores e a substituição das pastagens pode ser interpretada tanto como um enfraquecimento dessa cadeia produtiva, como da própria agricultura familiar desse município. Além disso, é preciso salientar que esta rápida conversão das pastagens em lavouras está atrelada a criação de uma psicosfera que legitima o discurso, valores e símbolos que fortalecem a territorialização do agronegócio e materializa seus resultados nos elevados índices de exportação de grãos deste município 9 . Esse contexto traz inseguranças para os agricultores familiares que optam por não se distanciar dos cultivos tradicionais desse modelo de produção, obrigando-os a recorrerem a algumas estratégias para permanecerem na terra.

\title{
Repercussões territoriais sobre os assentamentos e sobre a agricultura familiar
}

\begin{abstract}
de integração afirmada no Art. 21 que, conforme nos explica Sauer e Leite (2017, p.26), na prática, "abre a possibilidade que as famílias assentadas celebrem, ainda que de forma disfarçada, contratos de arrendamento, o que contraria a proposta original da Lei Agrária". De acordo com Leite (2018, p.3), "esses contratos rompem com o espírito constitucional do direito à terra, ou seja, a condição de explorar o imóvel diretamente como forma de geração de trabalho e renda para as famílias".

${ }^{9}$ De acordo com dados do Ministério da Economia, Indústria, Comércio Exterior e Serviços, sete municípios do Xingu- Araguaia foram responsáveis por gerar exportações que totalizaram uma receita no valor de 652,46 milhões de dólares em 2018, sendo que 62\% desse montante foi proveniente de Querência (Mdic, 2019).

${ }^{10}$ De acordo com Oliveira (2015, p.242), a monopolização do território é um processo decorrente da ação de empresas que "não produzem diretamente no campo, porém, controlam através de mecanismos de subordinação, a produção dos camponeses e dos capitalistas produtores do campo". Ou seja, essas empresas, notadamente as multinacionais como Bunge, Cargill, JBS S/A e a BRF S/A, não dispõe diretamente de terras, mas ao controlar toda a circulação das mercadorias, elas acabam controlando os atores que produzem no campo.

${ }^{11}$ Conforme Porto-Gonçalves (2010), para além das resistências que sugerem uma ação reativa por parte dos indivíduos e populações ameaçadas, a r-existência é a forma de existir e manifestarem plenamente seus modos de sentir, pensar e agir, isto é, trata-se de um modo de vida e de produção próprio.
\end{abstract}


O avanço da fronteira agrícola não é homogêneo no conjunto dos municípios e assentamentos do Xingu-Araguaia e cada um possui sua particularidade (sociohistórica, econômica e geofísica) que influencia o ritmo de expansão das commodities. Uma das características mais marcantes dos assentamentos de Querência é que a sua obtenção, realizada via mecanismos de desapropriação pelo não cumprimento da função social da terra, não foi precedida pela luta e ocupação de terra por famílias posseiras, conforme evidencia um entrevistado:

\footnotetext{
Os assentamentos de Querência eles têm um diferencial de Confresa, de São Félix porque nesses outros municípios teve um movimento social dentro. Então teve um movimento social que apoiou e organizou a luta pela terra. Aqui nunca teve nenhum movimento social de luta pela terra, aqui nunca foi isso. Aqui foi distribuição de terra, não teve movimento organizado que falou: "vamos organizar um assentamento, vamos ocupar essa área". O que teve aqui foi cortar a fazenda, distribuir e falar: "ô fulano, você quer um pedaço de terra", "você não tem nenhum parente que quer vir pra cá, não?” (...) nesses outros municípios, os movimentos organizaram e conversaram sobre a função social da terra. Aqui não. Aqui se você perguntar o que é função social da terra ninguém sabe o que é. (ENTREVISTADO 1, PESQUISA DE CAMPO, 2019).
}

Embora não seja pertinente generalizar, é possível afirmar que grande parte dos assentados desse município não compreende o assentamento em sua totalidade, enquanto um território da agricultura familiar e cuja política é fruto de um histórico de luta pela terra da classe trabalhadora e dos movimentos sociais. Essa constatação ainda é mais evidente entre aqueles assentados que têm migrado para o cultivo de grãos, onde seus vínculos são limitados à escala do lote, gerando um distanciamento entre as famílias e enfraquecimento desse vínculo territorial.

Outra importante repercussão sobre o território do recente processo de substituição de pastagens pela produção de grãos em Querência é a homogeneização do espaço, tornando inviável a diferenciação entre áreas da agricultura familiar, ou seja, os assentamentos, e áreas tradicionais, ao menos no que se diz respeito à paisagem. Essa homogeneização espacial possui três consequências diretas: a primeira é o esvaziamento físico e simbólico do assentamento diante do abandono do lote pelas famílias ou ainda que ela permaneçam lá, suas atividades estão mais vinculadas ao núcleo urbano; a segunda é o aprofundamento da especialização produtiva do município, indicando uma mudança nas relações de produção dentro do assentamento e um maior poder de controle dos agentes do agronegócio por 
meio de um processo de monopolização do território ${ }^{10}$ (OLIVEIRA, 2015), enfraquecendo a autonomia dos assentados que resistem a essa produção; por último, percebe-se que esse gradativo processo de expansão da fronteira agrícola dentro do assentamento leva a uma reconcentração fundiária, uma vez que não é raro encontrar diversos lotes sob o controle de apenas um proprietário que se dedica exclusivamente à produção de commodities.

O que se percebe em Querência é que existe uma subordinação, se não total, pelo menos parcial dos assentados que optam pela produção de commodities aos discursos e práticas do agronegócio, o que pode ser notado através dos contratos e valores que são repassados aos assentados ao final de cada safra. O contrato possui cláusulas fechadas e rigorosas que impõem uma série de ritmos, tempos, processos e linguagens vinculados somente a aspectos técnicos e funcionais que passam a conduzir a produção, o que faz com que o controle da produção e, consequentemente do lote (uma vez que optou-se pelo monocultivo) não seja exercido exclusivamente pela família assentada.

Diante disso, é conveniente citar o exemplo de uma moradora do PA Pingos d'Água que possuía, no momento da entrevista, dois lotes voltados para a produção de soja desde 2014, com contrato firmado com a Agro Amazônia, uma das principais empresas revendedoras de pacotes agrícolas do município. Antes, sua produção era de gado leiteiro e, posteriormente, gado de corte, mas decidiu converter a pastagem já degradada por considerar que os altos custos para reformar o pasto não compensariam o investimento. Em maio de 2019, ela já havia negociado o pacote para a safra de 2020 e os insumos, como sementes e adubos, já estavam chegando em seu lote para começar o preparo do solo e o plantio, a ser realizado em outubro do mesmo ano. Tanta antecedência na compra dos pacotes é com o objetivo de conseguir um preço mais vantajoso, uma vez que sua margem de lucro não é muito grande, visto que sua área de produção não ultrapassa 130 hectares. Segundo a entrevistada 2: “A gente conseguiu fazer um pacote melhor porque foi no início do ano, aí os preços estavam bons, mas se você deixar prá fechar agora aí fica mais caro. É tudo muito planejado, antes de terminar de colher a gente já tinha fechado”(PESQUISA DE CAMPO, 2019).

Por trás desse planejamento presente em toda a safra encontra-se a racionalidade embutida não só no processo produtivo como também no próprio espaço geográfico, como nos lembra Santos (2014). Esse espaço racional supõe um centro de comando e 
uma ação instrumentalizada por meio das técnicas e faz com que cada vez mais o meio rural seja artificializado e sem mistérios, uma vez que o "respeito tradicional às condições naturais cede lugar, em proporções diversas, segundo os produtos e as regiões, a um novo calendário agrícola baseado na ciência, na técnica e no conhecimento" (SANTOS, 2014, p.305). Neste espaço não há lugar para o improviso, para a diversificação, para o cuidado e saber tradicional e compartilhado e para o ritmo de uma produção livre de agrotóxicos. Nessa lógica racional, onde cada ação almeja o aumento da produtividade e da rentabilidade, quem controla a produção é aquele que além de determinar os ritmos, absorve a maior parte do lucro e qualquer prejuízo ou imprevisto que ocorra durante a safra é arcado exclusivamente pelo produtor que vê a sua margem de lucro, já pequena, se reduzir ainda mais, conforme explica a assentada:

\begin{abstract}
Essa safra saiu o pacote para nós numa estimativa que a gente colheria 60 sacas/hectare, 35 seria da empresa. Se a gente colhesse 60 . Mas tem pessoas que colhe mais, colhe 70 . Se a gente já colhesse 65 , aí eu conseguiria aumentar meu lucro, por isso a gente tem que cuidar muito da planta, da produção, mas é mais ou menos isso ai. Desses 25 de lucro a gente ainda paga várias outras coisas. Ano passado ficou média de 30 para nós, eu tive que pagar frete, diesel e essas coisas. No final vai sobrar de 10 a 15 sacas para mim. ((ENTREVISTADA 2, PESQUISA DE CAMPO, 2019).
\end{abstract}

Em outras palavras, $58 \%$ do lucro da produção é direcionado para o pagamento do pacote dos insumos adquiridos para a lavoura. Dos $42 \%$ que seriam de lucro da assentada e sua família, ou seja, uma média de 25 sacas/hectare, aproximadamente a metade é destinada para cobrir outros custos, exemplificados na fala acima. Diante da falta de armazenamento próprio, a autonomia do assentado para negociar o seu produto e vendê-lo quando o preço for mais favorável fica ainda mais limitada, sendo mais um indicativo de que o controle da produção não está com os produtores, sobretudo os menores. A relação com a empresa fica bem clara na fala a seguir da entrevistada, que também indica a percepção sobre a sua própria subordinação:

A Agro Amazônia que fornece para gente ela tinha uma salinha pequeninha,
agora é enorme. Quem planta mesmo fica com pouco, eles ficam lá sem fazer
nada. Se fizer chuva, se fizer sol, quem não dorme é você. Eles dormem
tranquilos porque eles vão receber. Eles vão receber ou então eles acabam com
a sua vida. Eles fazem você vender tudo que você tem para pagar eles.
(ENTREVISTADA 2, PESQUISA DE CAMPO, 2019).

Vale ainda mencionar que a aquisição de novas áreas é a estratégia encontrada não somente por essa entrevistada, mas também por outros assentados que arrendam terras 
dentro do assentamento para conseguir aumentar o seu lucro. Ou seja, o incremento da renda familiar através do aumento do rendimento e produtividade por hectare é secundário nessa lógica, que prioriza o incremento da área plantada, movimentando a fronteira em direção a outras áreas. Isso demonstra que o avanço da fronteira não tem sido realizado somente por grandes produtores e grupos empresariais, mas também por pequenos produtores assentados.

Essa expansão é acompanhada pela intensificação do uso dos agrotóxicos que provoca um efeito desarticulador dentro dos assentamentos na medida em que provoca uma série de prejuízos econômicos para os agricultores familiares através dos danos às suas produções. De acordo com Bombardi (2017), em 2015, cerca de 52\% de todo o agrotóxico vendido no país era destinado à produção de soja, com destaque para o glifosato. No Araguaia-Xingu não é diferente, a ponto do entrevistado 3 afirmar que "aqui é impossível plantar soja sem glifosato" (PESQUISA DE CAMPO, 2019), lembrando que a maior parte das sementes comercializadas nos pacotes agrícolas nessa região são transgênicas. A deriva dos agrotóxicos, sobretudo aquela decorrente da pulverização aérea e seu maior alcance, aparece como um dos principais temores para os agricultores familiares, como demonstrado por um entrevistado do PA Brasil Novo:

(...) o meu medo é que eles comecem a fazer a pulverização aérea. Aí tá só o meu lotezinho ali no meio e avião pulverizando de lá, de cá, você vai ficar no meio de uma cortina de veneno e ai ao invés de você melhorar a sua qualidade de vida, você vai se matar (ENTREVISTADO 4, PESQUISA DE CAMPO, 2019).

Enquanto isso, outro assentado do PA Pingos d'Água confirma esse temor e diante de sua preferência em não migrar para a produção de grãos, admite que já procura outros lotes em assentamentos dos municípios vizinhos, indicando um processo de expropriação de terras ligada ao avanço da fronteira. Isso demonstra que enquanto no PA Brasil Novo (mais distante do núcleo urbano de Querência) a intensificação do uso dos agrotóxicos ainda é um temor, no PA Pingos d'Água, isso já é uma realidade que a agricultura familiar tem dificuldades de enfrentar.

No entanto, ainda não é possível afirmar que a totalidade dos assentados converteram ou converterão seus lotes, mesmo sabendo que o assédio e pressão por isso seja uma realidade. Dois motivos nos permitem essa afirmação: o primeiro é que durante os trabalhos de campo, foi possível constatar a existência de alguns lotes com a produção 

assentamentos rurais na fronteira agrícola

frutas e hortaliças (foto 2) que, em geral, são destinadas para o abastecimento das feiras livres e pequenos estabelecimentos comerciais do município que, todavia, recebe diariamente produtos provenientes da Central de Abastecimento (Ceasa) de Goiânia, que fica a mais de $800 \mathrm{~km}$ de distância do município.

Foto 2 - Querência: produção de hortaliças no PA Pingos d'Água

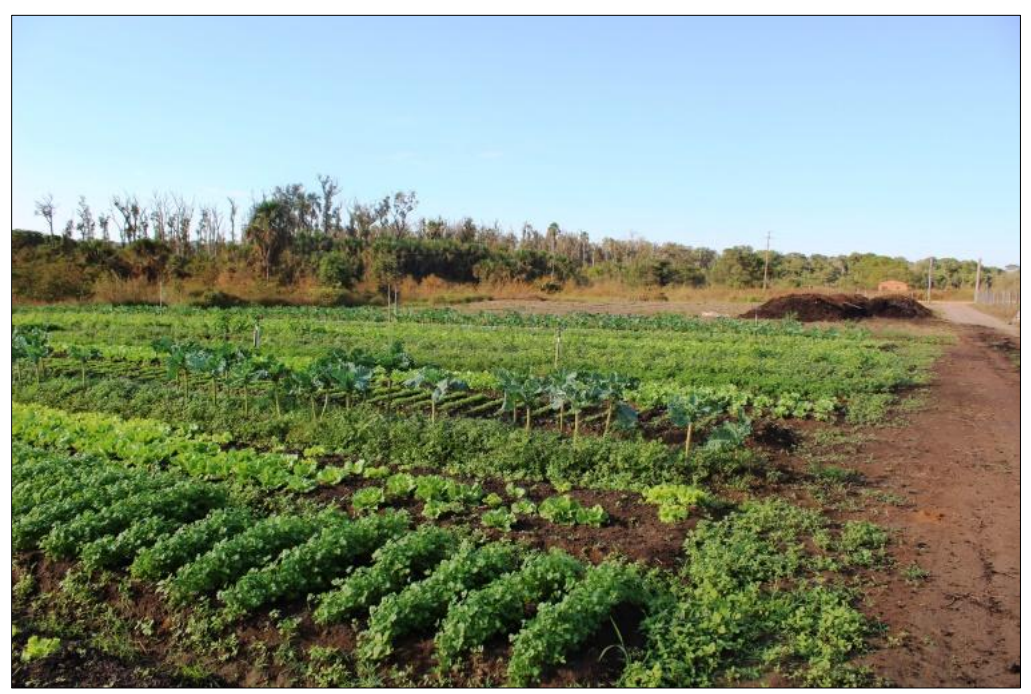

Fonte: Pesquisa de campo, 2019.

Autora: Taiana Lourenço.

Pela sua proximidade do núcleo urbano do município, a produção familiar originada no PA Pingos d'Água é mais fácil de ser comercializada do que aquela produzida no PA Brasil Novo. Exatamente por ser ter essa proximidade, esses cultivos disputam mais acirradamente espaço com as lavouras que predominam nesse assentamento e, consequentemente, são atingidos mais diretamente pela deriva aérea de agrotóxicos utilizados nas plantações. Ainda assim, os agricultores familiares buscam ampliar suas opções de geração de renda a partir da diversificação produtiva:

\footnotetext{
A nossa opção é diversificar, é vender a polpa do cupuaçu, do açaí, da graviola, vender um milho verde, a mandioca, de repente pode plantar um feijão também que entra na rotação de cultura mais o gado e se ele inviabilizar você pode entrar com o carneiro, você pode ter um número maior de animais. Conforme o mercado apontar você pode fazer uma coisa ou outra. (ENTREVISTADO 4, PESQUISA DE CAMPO, 2019).
}

O segundo motivo é que esses assentados que persistem consoantes às práticas da agricultura familiar rechaçam veementemente a conversão dos lotes nos moldes que ela tem sido realizada no município o que os impulsiona a estabelecer novas redes e parcerias 
que fortalecem suas decisões e a autonomia familiar. Os vínculos com atores locais, como o Instituto Federal de Mato Grosso - Campus Confresa, Comissão Pastoral da Terra, Instituto Socioambiental, Prelazia de São Félix do Araguaia, Rede de Sementes do Xingu, prefeituras, secretarias de meio ambiente e outras organizações não governamentais locais, endogeniza os laços territoriais que contribuem para o fortalecimento da agricultura familiar a partir do compartilhamento de saberes e união entre os assentados que questionam o modelo implementado pelo agronegócio.

Isso direciona essa agricultura familiar a dotar de centralidade a agroecologia e a prática coletiva, não somente como uma técnica produtiva, mas como elementos fundamentais para a sua sobrevivência, r-existência ${ }^{11}$ e diferenciação. Ainda nesta direção, é consenso entre os entrevistados que a diversificação produtiva com base nos sistemas agroflorestais é o melhor caminho a ser seguido pela agricultura familiar. Contudo, ainda que essa diversificação tenha o potencial de fornecer mais oportunidades às famílias, melhorando a sua qualidade de vida, o seu local e a própria região em que está inserida, ela é dependente de um processo contínuo de negociações e redefinições da relação familiar, gênero, poder e propriedade (PERONDI e SCHNEIDER, 2015). Em outras palavras, a diversificação produtiva é uma escolha familiar que pode encontrar alguns obstáculos, técnicos e culturais até a sua implementação, mas ainda sim, uma prática capaz de estabelecer uma importante diferenciação de posicionamento nas regiões de fronteira agrícola.

Outro elo de fortalecimento da agricultura familiar do município é a Cooperativa Agropecuária de Querência, cujo estatuto é totalmente voltado para as demandas da agricultura familiar do município. Essa cooperativa foi criada em 2009 e atende aproximadamente 35 famílias, majoritariamente assentadas, algumas com a produção de pupunha e outras a produção leiteira. Mesmo sendo um exemplo de êxito, existem dificuldades no trabalho da cooperativa, como: redução na adesão de novos associados e empecilhos políticos locais que não priorizam iniciativas para a agricultura familiar, como a construção de um laticínio no município, o que, segundo o entrevistado 4 , fomentaria a participação de outros agricultores.

O incentivo à cadeia produtiva leiteira e outras relacionadas à agricultura familiar é uma das propostas contidas no "Plano Municipal da Agricultura Familiar e dos Povos Indígenas" publicado em 2019. Todavia, a despeito da existência desse documento 
que estabelece diretrizes e planejamentos futuros para esse público, a realidade municipal demonstra que os esforços do poder público são preferencialmente direcionados para o agronegócio. Tal constatação também é a de um dos entrevistados que, sobre o plano supracitado, afirma que: "papel aceita tudo, né?! Você enche de coisa aqui, mostra lá, faz um evento pra todo mundo ver e depois bota na gaveta" (ENTREVISTADO 4, PESQUISA DE CAMPO, 2019).

Neste sentido, é mais do que fundamental para a agricultura familiar praticada nos assentamentos desse município a endogeneização das relações sociais a partir da construção e fortalecimento de redes locais, ampliando a percepção da importância e da coletividade representadas pelo assentamento enquanto território da agricultura familiar.

\section{Considerações finais}

O avanço da fronteira agrícola sobre os assentamentos rurais de Querência tem colocado os agricultores familiares diante de novos desafios, como a deriva de agrotóxicos das lavouras vizinhas às suas produções. Outros desafios, no entanto, não são tão antigos, como a constante necessidade de reafirmar seus posicionamentos e desejos de perpetuar, através das gerações, o vínculo com a terra. Este artigo buscou debruçar-se sobre algumas dessas questões que atingem o cotidiano e a vida de agricultores e assentamentos na região Xingu-Araguaia.

Esse processo se acelerou no início dos anos 2000 e vem promovendo uma homogeneização espacial decorrente da conversão das pastagens já degradadas em lavouras de grãos. Se, por um lado essa conversão pode ser entendida como uma estratégia de assentados para permanecerem na terra, por outro ela deve ser lida num contexto mais amplo, como sendo mais uma estratégia de reprodução ampliada do capital, onde o controle da produção é determinante para confirmar a submissão do produtor à lógica do modo de produção capitalista. Isso, por sua vez, modifica as relações que o assentado/agricultor precisa estabelecer e conhecer essas relações são fundamentais para determinar o significado que o assentamento adquire para cada família.

No contexto no qual a política de assentamentos rurais está inserida e tendo em vista os seus objetivos, é fundamental que os assentados obtenham garantias de que a sua reprodução familiar será conquistada através do trabalho no lote, o que reforça os laços com o assentamento enquanto um território da agricultura familiar. A produção de commodities 
em larga escala dentro dos assentamentos coloca em risco essas garantias diante de fatores como o uso de agrotóxicos e a pressão pelo arrendamento e venda dos lotes para serem incorporados a essa produção. Nesse sentido, sabendo que os interesses do agronegócio e da agricultura familiar são distintos, bem como a forma como eles compreendem a terra, podese concluir que o avanço da fronteira agrícola dentro dos assentamentos não somente ameaça a agricultura familiar como também faz com que a coexistência desses dois modelos seja um fator de possíveis conflitos locais.

\section{Agradecimentos}

Agradeço ao Conselho Nacional de Desenvolvimento Científico e Tecnológico (CNPq) e à Coordenação de Aperfeiçoamento de Pessoal de Nível Superior (CAPES) pela concessão de bolsa de pesquisa durante o período de doutorado.

\section{REFERÊNCIAS}

BECKER, Bertha. O Estado e a questão da terra na fronteira: uma contribuição geopolítica. IN: VIEIRA, I.C.G. (org). As Amazônias de Bertha K. Becker: ensaios sobre a geografia e a sociedade na região amazônica. $1^{a}$ ed. Vol.1. Rio de Janeiro: Garamond, 2015.

BOMBARDI, Larissa. Geografia do Uso de Agrotóxicos no Brasil e Conexões com a União Europeia. 1. ed. São Paulo: Laboratório de Geografia Agrária, 2017. v. 1. 296p.

BRASIL. Medida Provisória $\mathbf{n}^{0}$ 910, de 10 de dezembro de 2019. Altera a Lei $\mathrm{n}^{\circ}$ 11.952 , de 25 de junho de 2009, que dispõe sobre a regularização fundiária das ocupações incidentes em terras situadas em áreas da União, a Lei $\mathrm{n}^{\circ} 8.666$, de 21 de junho de 1993, que institui normas para licitações e contratos da administração pública, e a Lei $n^{\circ}$ 6.015, de 31 de dezembro de 1973, que dispõe sobre os registros públicos. Disponível em: https://www.in.gov.br/en/web/dou/-/medida-provisoria-n-910-de-10-dedezembro-de-2019-232671090 . Acesso em 08 de abr.2021.

Medida Provisória no 759, de 22 de dezembro de 2016. Dispõe sobre a regularização fundiária rural e urbana, sobre a liquidação de créditos concedidos aos assentados da reforma agrária e sobre a regularização fundiária no âmbito da Amazônia Legal, institui mecanismos para aprimorar a eficiência dos procedimentos de alienação de imóveis da União, e dá outras providências. Disponível em: http://www.planalto.gov.br/ccivil_03/_Ato2015-2018/2016/Mpv/mpv759.htm Acesso em 08 de abr.2021.

COMISSÃO PASTORAL DA TERRA. Cadernos conflitos no campo. 2020. Disponível em: https://www.cptnacional.org.br/publicacoes-2/destaque/5167-conflitosno-campo-brasil-2019. Acesso em abril/2020. 
DELGADO, Guilherme da Costa. Do Capital Financeiro na Agricultura à Economia do Agronegócio: Mudanças Cíclicas em Meio Século: (1965-2012). 1a. ed. Porto Alegre - RS: Editora da UFRGS, 2012. v. 01. 142p.

FERNANDES, Bernardo Mançano. Questões teórico-metodológicas da pesquisa geográfica em assentamentos de reforma agrária. IN: Revista NERA (UNESP), NERA/UNESP, v. 1, n.2, p. 1-32, 1998.

. Cuando la agricultura familiar es campesina. In: HIDALGO, F.; HOUTART, F.; LIZÁRRAGA, P. A.. (Org.). Agriculturas campesinas en Latinoamérica: propuestas y desafíos. 1ed.Quito: Editorial IAEN,, 2014, v. 1, p. 1934.

HAESBAERT, Rogério. Des-territorialização e identidade: a rede gaúcha no Nordeste. Niterói: EdUFF, 1997. 293 p.

JEPSON, Wendy. Producing a modern agricultural frontier: firms and cooperatives in Eastern Mato Grosso, Brazil. IN: Economic Geography, nº82, p.289-316, 2006.

LEITE, Acácio Zuninga. Decreto 9.311/2018: a legalização da especulação das terras carimbadas para a reforma agrária. Florianópolis: Núcleo de Estudos de Economia Catarinense, 2018. (Texto para Discussão 02/2018).

MARTINS, Edilson. Nós, do Araguaia. Pedro Casaldáliga: o Bispo da Teimosia e da Liberdade. Rio de Janeiro: edições Graal, 1979.

MARTINS, José de Souza. Impasses políticos dos movimentos sociais na Amazônia. IN: Tempo Social; Revista de Sociologia USP. São Paulo, v.1 (1), 1989. p.131-148

São Paulo: Contexto, 2012. $2^{\mathrm{a}}$ ed.

. Fronteira: a degradação do outro nos confins do humano.

MONTE, Francisco Clesson Dias. O INCRA e a política de assentamentos rurais: um estudo sobre processos político-administrativos de ação pública. Tese (Doutorado). Universidade Federal Rural do Rio de Janeiro, Instituto de Ciências Humanas e Sociais. 2013. 234p.

MORENO, Gislene. Terra e poder em Mato Grosso: politica e mecanismos de burla (1892-1993). Cuiabá: Entrelinhas/ed. UFMT, 2007.

NIEDERLE, Paulo; WESZ Jr., Valdemar. As novas ordens alimentares. 1. ed. Porto Alegre: UFRGS, 2018. v. 1. 432p.

OLIVEIRA, Ariovaldo Umbelino. A fronteira amazônica brasileira: grilagem, corrupção e violência. 1. ed. São Paulo: Iãnde Editorial, 2016a. v. 1. 475p.

A mundialização do capital e a crise do neoliberalismo: o lugar mundial da agricultura brasileira. GEOUSP: espaço e tempo, v. 19, p. 228-244, 2015. 
PERONDI, Miguel Ângelo; SCHNEIDER, Sérgio. Diversificação agrícola e não agrícola da agricultura familiar. IN: SCHNEIDER, S.; GAZOLLA, M. (orgs). Os atores do desenvolvimento rural: perspectivas teóricas e práticas sociais. Porto Alegre: Editora da UFRGS, 2011. pp. 2015-220.

PORTO-GONÇALVES, Carlos Walter. A Reinvenção dos Territórios: a experiência latino-americana e caribenha. In: Agripino Souza Coelho Neto; Edinusia Moreira Carneiro Santos; Onildo Araújo da Silva. (Org.). Geografias dos movimentos sociais. $1^{\mathrm{a} e d .}$ Feira de Santana - BA: UEFS Editora, 2010, v. 1, p. 15-152.

RIVIÈRE D'ARC, Hèlene.; APESTÉGUY, Christine.. Les nouvelles franges pionnières en Amazonie brésilienne. La vallée de 1'Araguaia. Études rurales, n69, 1978. pp. 81100.

SANTOS, Milton. A natureza do espaço. Técnica e tempo, razão e emoção. São Paulo: Editora da Universidade de São Paulo. 2014. $4^{\text {a }}$ ed.

SAUER, Sérgio.; LEITE, Acácio Zuninga. MP 759: Descaminhos da reforma agrária e legalização da grilagem de terras no Brasil. IN: Retratos de assentamentos. V.20, ${ }^{\circ} 1$, 2017.

SVAMPA, Maristella. "Consenso de los Commodities" y linguajes de valoración en América Latina. IN: Nueva Sociedad, n²44, marzo/abril, 2013. p.30-46. 